\title{
Current management of shoulder adhesive capsulitis: a randomized, triple-blind placebo-controlled trial
}

\author{
Riyadh A. Almashni ${ }^{1 *}$, Abdullah W. Calacattawi ${ }^{2}$, Meshal A. Almeshal ${ }^{3}$, Elaf J. Alsharif ${ }^{4}$, \\ Mohamad W. Hijazi ${ }^{5}$, Shahd A. Abdulwahab ${ }^{5}$, Anfal J. Alsharif ${ }^{6}$, Nasser O. Altufayl ${ }^{7}$, \\ Anwar A. Alghamdi ${ }^{1}$, Hisham A. Almuzayyen ${ }^{8}$
}

\author{
${ }^{1}$ Al-baha University, Medical College of Al-baha University, Albaha, Saudi Arabia \\ ${ }^{2}$ King Abdulaziz University, Medical College of King Abdulaziz University, Jeddah, Saudi Arabia \\ ${ }^{3}$ Almajmaah University, Medical College of Almajmaah University, Almajmaah, Saudi Arabia \\ ${ }^{4}$ Ibn Sina National College, Medical College of Ibn Sina National College, Jeddah, Saudi Arabia \\ ${ }^{5}$ Almaarefa Colleges, Medical College of Almaarefa colleges, Riyadh, Saudi Arabia \\ ${ }^{6}$ Umm Al Qura University, Medical College of Umm Al Qura University, Makkah, Saudi Arabia \\ ${ }^{7}$ King Khalid University, Medical College of King Khalid University Abha, Saudi Arabia \\ ${ }^{8}$ Imam Abdulrahman Bin Faisal University, Medical College of Imam Abdulrahman Bin Faisal University, Dammam, \\ Saudi Arabia
}

Received: 15 July 2018

Revised: 28 July 2018

Accepted: 30 July 2018

*Correspondence:

Dr. Riyadh A. Almashni,

E-mail: iRiyadhx@outlook.com

Copyright: (C) the author(s), publisher and licensee Medip Academy. This is an open-access article distributed under the terms of the Creative Commons Attribution Non-Commercial License, which permits unrestricted non-commercial use, distribution, and reproduction in any medium, provided the original work is properly cited.

\begin{abstract}
This review is aiming to discuss both operative and non-operative current management of this adhesive capsulitis. The present review was conducted in accordance with the preferred reporting items for systematic reviews and metaanalyses (PRISMA) declaration standards for systematic reviews. A systematic search for the terms adhesive capsulitis, frozen shoulder, glucocorticoid, non-operative operative, current management, and management of systematic review in different databases, including MEDLINE, EMBASE and the Cochrane Central Register of Controlled Trials (CENTRAL), were searched up to March 2018 for published and unpublished studies and without language restrictions. The majority of the trials show level 2 [mid-level] evidence, positive results were found for intra-articular corticosteroid injections combined with shoulder mobility and stretching exercises are more effective in providing short-term (4-6 weeks) pain relief and improved function compared to shoulder mobility and stretching exercises alone. On the basis of current clinical evidence, this systematic review suggests that there is no strong evidence to support or refute the current practice in term of adhesive capsulitis management. As there is a need of further research in this issue and to have clear uniformed prospective about the adhesive capsulitis.
\end{abstract}

Keywords: Adhesive capsulitis, Frozen shoulder, Intra-articular glucocorticoid, Operative management

\section{INTRODUCTION}

Adhesive capsulitis also known as frozen shoulder is a musculoskeletal condition that has a disabling capability, which characterized by a painful, gradual restriction of both active and passive movements of the glenohumeral joint. Idiopathic frozen shoulder is the most common cause of painful restriction of the shoulder movement and is characterized by an inflammatory contracture of the shoulder capsule and ligaments, causing a reduction in the available intra-articular volume, and limitation of the glenohumeral movement. ${ }^{1}$ 
The Incidence of the adhesive capsulitis is Uncommon in general population, estimated $2 \%$ annual incidence in Scandinavian population at risk. common in patients with diabetes; cross-sectional study in 291 patients with type I diabetes (mean age 33) and 134 patients with type II diabetes (mean age 61), prevalence of shoulder capsulitis was $10.3 \%$ in patients with type I and $22.4 \%$ in patients with type II diabetes, adhesive capsulitis detected in $29 \%$ of cohort with type 2 diabetes in outpatient diabetic clinic in Turkey. 2,3

Adhesive capsulitis may be associated with increased risk of stroke based on prospective cohort study, 10,935 patients $>40$ years old with adhesive capsulitis and no history of rheumatologic disorder in past year or any history of stroke and 32,805 controls followed for 3 years; stroke in $5.3 \%$ with adhesive capsulitis vs. $3.7 \%$ controls $(\mathrm{p}=0.002){ }^{4}$

As there are many accepted standard forms of management for shoulder disorders, including nonsteroidal anti-inflammatory drugs, corticosteroid injections, and physiotherapy, yet evidence of their efficacy is not well established, and Because there is little evidence to support or refute the efficacy of common current interventions for shoulder pain and management of Adhesive capsulitis we conducted this review discusses both operative and non-operative current management of this shoulder condition, aiming to clarify What is the types of current available management for adhesive capsulitis, the effectiveness of non-operative treatment for Adhesive Capsulitis, and treatment prognosis on pain relief and range of motion improvement.

\section{Etiology and pathogenesis}

Evidence from previous studies showed that most of the cases of adhesive capsulitis are idiopathic, which could not be linked to a specific cause. ${ }^{5}$ However multiple cases have been linked to disuse pathological process that follows prolonged shoulder immobilization. This is usually accompanied by complex regional pain syndrome. In addition, some cases have been linked to vascular insufficiency. ${ }^{5}$

The pathogenesis of adhesive capsulitis include adhesions and fibrotic, restrictive changes in the shoulder capsule. However, some cases may have no clear pathology. ${ }^{5}$ Capsular inflammation may lead to adherence of capsule to anatomic neck of humerus and itself at the inferior axillary fold. ${ }^{5}$

Frozen shoulder is typically characterized as having three overlapping phases: ${ }^{6}$

Phase 1: in which there is progressive stiffening and loss of motion in the shoulder with increasing pain on movement, which may be worse at night (months 2-9), usually referred to as the painful phase.
Phase 2: in which there is a gradual decrease in pain but stiffness remains and there is considerable restriction in the range of movement (months 4-12), usually referred to as the stiffening or 'freezing' phase

Phase 3: in which there is an improvement in range of movement (months 12-42), usually referred to as the resolution phase.

\section{METHODS}

The present review was conducted in accordance with the Preferred Reporting Items for Systematic Reviews and Meta-Analyses (PRISMA) declaration standards for systematic reviews. A systematic search for the terms adhesive capsulitis, frozen shoulder, glucocorticoid, nonoperative operative, current management, and management of systematic review in different databases, including MEDLINE, EMBASE and the Cochrane Central Register of Controlled Trials (CENTRAL), were searched up to March 2018 for published and unpublished studies and without language restrictions. The websites of relevant organizations were scanned. The reference lists of systematic reviews were also checked to identify studies. Updated searches of MEDLINE, Google Scholar and EMBASE were undertaken in July, 2018, In terms of the PICOS formula (patient, intervention, comparator, outcome, study design), the search strategy focused on population and intervention.

Studies has been independently rated as being high quality by an established evaluation process based on the DynaMed criteria (www.dynamed.com) and it's about levels of evidence, as following:

Level A (randomized controlled trial/meta-analysis): High-quality randomized controlled trial (RCT) that considers all important outcomes. High-quality metaanalysis (quantitative systematic review) using comprehensive search strategies.

Level B (other evidence): A well-designed, nonrandomized clinical trial. A non-quantitative systematic review with appropriate search strategies and well-substantiated conclusions. Includes lower quality RCTs, clinical cohort studies, and case-controlled studies with non-biased selection of study participants and consistent findings. Other evidence, such as high-quality, historical, uncontrolled studies, or well-designed epidemiologic studies with compelling findings, is also included.

Level C (consensus/expert opinion): Consensus viewpoint or expert opinion.

\section{Inclusion criteria}

Inclusion criteria were idiopathic adhesive capsuliti; age15 to 70 years; males and females patients. 


\section{Exclusion criteria}

Exclusion criteria were other condition involving shoulder such as rheumatoid arthritis, damage of glenohumeral cartilage, osteoporosis; neurologic deficit affecting shoulder function; patients with shoulder girdle; malignancy.

\section{Data extraction and analysis}

Information relating to each of the systematic review question elements was extracted from the studies and collated in qualitative tables. Direct comparisons between studies of adhesive capsulitis must be made with extreme caution, as different sampling techniques can provide a bias overview of the assemblage.

\section{RESULTS}

\section{Management of adhesive capsulitis}

There are a number of management options, both operative and non-operative, but there is no consensus about management. For the purpose of the report we have classified the interventions as conservative and invasive (Table 1).

The results of the papers found in the systematic search were grouped in a thematic analysis methodology. These include the conservative treatment group which discuss steroid injection as the main method (Table 2), and invasive treatment, which include hyaluronate injection and nerve block (Table 3)

Table 1: Classification of interventions for frozen shoulder.

\begin{tabular}{|ll|}
\hline \multirow{4}{*}{ Conservative treatment } & $\begin{array}{l}\text { Steroid injections. } \\
\text { Physical therapy. }\end{array}$ \\
\hline \multirow{4}{*}{ Invasive treatment } & Acupuncture. \\
\hline & Sodium hyaluronate \\
\hline & MUA \\
\hline & Distension \\
\hline & Capsular release \\
\hline
\end{tabular}

\section{Conservative treatment}

Manual therapy and exercise in combination and alone have limited evidence to guide treatment of adhesive capsulitis.

Based on a Cochrane systematic review of 32 randomized or quasi-randomized trials evaluating manual therapy or exercise in 1,836 adults with adhesive capsulitis, only few trials compared same combination of interventions, and many comparisons were limited by small sample sizes. $^{7}$ only 1 trial compared manual therapy plus exercise to placebo. Manual therapy plus exercise significantly increased self-reported treatment success compared to sham ultrasound following arthrographic joint distention. ${ }^{7}$

However, there were no significant differences in pain and function in another trial including 156 adults. The observed differences were only short term differences in pain and/or function. ${ }^{7}$ This was seen as improved overall pain and function at 6 weeks with combination of manual therapy, exercise, electrotherapy, and glucocorticoid injection vs. placebo injection in analyses of 2 trials with 78 adults. Another trail (107 adults) showed smaller improvement in pain and function at 6 weeks with manual therapy plus exercise vs. glucocorticoid injection. In addition, there was statistically significant but clinically unimportant decrease in function at 6 weeks with combination of manual therapy, exercise, and electrotherapy compared to glucocorticoid injection in analysis of 2 trials with 86 adults. ${ }^{7}$ There were statistically non-significant increase in treatment success at 6 weeks with addition of manual therapy, exercise, and electrotherapy to oral ibuprofen in 1 trial with 122 adults. $^{7}$

Comparisons evaluating effect of manual therapy and exercise individually showed that the addition of anterior or posterior glide mobilization to exercise plus electrotherapy significantly reduced pain at 3 weeks in 1 trial with 45 adults. In addition, combining end-range and scapular mobilization to exercise plus electrotherapy significantly improved function at 8 weeks in a trial involving 23 adults. Moreover, the addition of scapulothoracic exercises to range of motion exercises, electrotherapy, cold pack, and nonsteroidal antiinflammatory drugs significantly reduced pain at 6-12 weeks in 1 trial with 29 adults. Studies also showed that dumbbell exercises significantly increased treatment success at 3 months vs. bare-handed exercises in 1 trial with 54 adults. ${ }^{7}$

Oral steroids significantly less effective than intraarticular steroid injection at 1 week in 1 trial with 28 patients. ${ }^{8,9}$

Oral steroid regimen of triamcinolone $4 \mathrm{mg} 3$ times daily for 1 week, twice daily for 1 week then once daily for 1 week showed a Cure rates $13 \%$ vs. $62 \%(\mathrm{NNH} 2)$ at 1 week. Studies showed non-significant trends that favor intra-articular injection at 2 weeks (60\% vs. $92 \%)$ and 3 weeks $(80 \%$ vs. $100 \%)$.

\section{Physical therapy and energy modalities}

Australian Physiotherapy Association recommends against providing ongoing manual therapy for patients with adhesive capsulitis of the shoulder (Choosing Wisely Australia 2016 March 1). 
Table 2: Description of published randomized controlled trials of steroid injections for adhesive capsulitis.

\begin{tabular}{|c|c|c|c|c|c|}
\hline $\begin{array}{l}\text { Study and date } \\
\text { published }\end{array}$ & $\begin{array}{l}\text { Number of } \\
\text { shoulders }\end{array}$ & Interventions & Outcomes measured & Findings & $\begin{array}{l}\text { Levels of } \\
\text { evidence }\end{array}$ \\
\hline Yaying et al $^{13}$ & 416 & $\begin{array}{l}\text { Single intra-articular } \\
\text { injection }\end{array}$ & $\begin{array}{l}\text { Pain relief scores: 0-10 } \\
\text { point scale with higher } \\
\text { score indicating worse } \\
\text { pain } \\
\text { - Adverse effects }\end{array}$ & $\begin{array}{l}\text { - Intra-articular steroid injection associated with } \\
\text { improved Shoulder Pain and Disability Index score } \\
\text { at 4-6 weeks, 12-16 weeks, 24-26 weeks (mean } \\
\text { difference } 16.62,13.46,9.91 \text { points respectively) } \\
\text { - Side effects included facial flushing, dizziness, chest } \\
\text { or shoulder pain, or nausea }\end{array}$ & $\begin{array}{l}\text { level } 2 \text { [mid- } \\
\text { level] } \\
\text { evidence }\end{array}$ \\
\hline Prestgaard et al $^{14}$ & $\begin{array}{l}122 \text { adults aged } \\
25-70 \text { years }\end{array}$ & $\begin{array}{l}\text { Intra-articular and } \\
\text { combined intra- } \\
\text { articular/rotator cuff } \\
\text { interval corticosteroid } \\
\text { injections }\end{array}$ & $\begin{array}{l}\text { - Shoulder pain (scale 0- } \\
10 \text { points) } \\
\text { - Shoulder pain and } \\
\text { disability index (spadi; } \\
\text { scale } 0-100 \text { points, } \\
\text { higher score indicates } \\
\text { worse pain and } \\
\text { disability) } \\
\text { - Adverse effects }\end{array}$ & 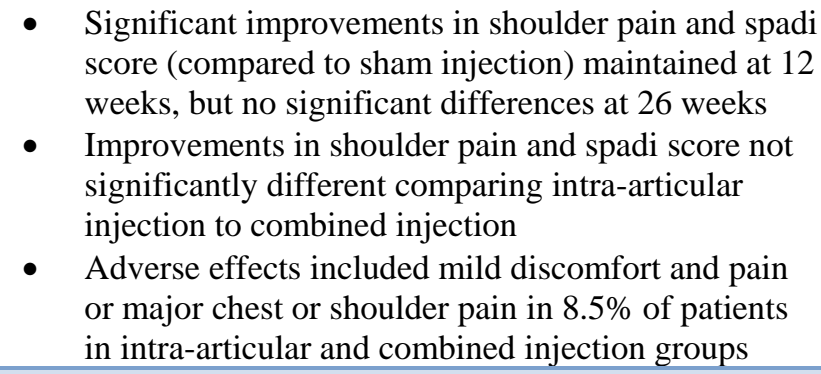 & $\begin{array}{l}\text { level } 2 \text { [mid- } \\
\text { level] } \\
\text { evidence }\end{array}$ \\
\hline Grant et al ${ }^{10}$ & 191 & $\begin{array}{l}\text { Ultrasonography- } \\
\text { guided corticosteroid } \\
\text { injection may reduce } \\
\text { pain compared to oral } \\
\text { aceclofenac }\end{array}$ & $\begin{array}{l}\text { - Shoulder pain score } \\
\text { - Shoulder function score } \\
\text { - } \\
\text { Patient satisfaction } \\
\text { score }\end{array}$ & 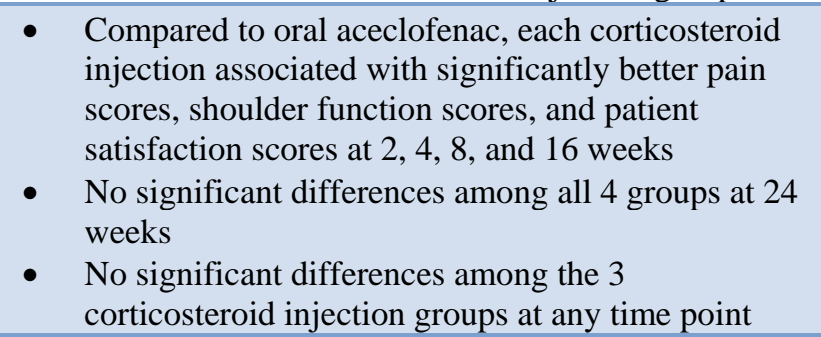 & $\begin{array}{l}\text { level } 2 \text { [mid- } \\
\text { level] } \\
\text { evidence }\end{array}$ \\
\hline
\end{tabular}


Table 3: Description of published randomized controlled trials of other medications for adhesive capsulitis.

\begin{tabular}{|c|c|c|c|c|c|}
\hline $\begin{array}{l}\text { Study and date } \\
\text { published }\end{array}$ & $\begin{array}{l}\text { Number of } \\
\text { shoulders }\end{array}$ & Interventions & Outcomes measured & Findings & $\begin{array}{l}\text { Levels of } \\
\text { evidence }\end{array}$ \\
\hline Mun, Baek ${ }^{11}$ & 591 & $\begin{array}{l}\text { Suprascapular nerve } \\
\text { block }\end{array}$ & $\begin{array}{l}\text { - } \text { Pain reduction } \\
\text { - Functional improvement } \\
\text { - Adverse effects }\end{array}$ & $\begin{array}{l}\text { Suprascapular nerve block associated with significant } \\
\text { reduction in pain at } 1 \text { week, } 4 \text { weeks, } 12 \text { weeks. There } \\
\text { were consistent effects for functional improvement } 1,4 \text {, } \\
\text { and } 12 \text { weeks after intervention. Adverse events included } \\
\text { mostly bruising or discomfort near puncture site }\end{array}$ & $\begin{array}{l}\text { Level } 2 \\
\text { [mid-level] } \\
\text { evidence }\end{array}$ \\
\hline Grant et al $^{10}$ & 100 & $\begin{array}{l}\text { Intra-articular } \\
\text { injection of } \\
\text { hyaluronate plus } \\
\text { capsular distention }\end{array}$ & $\begin{array}{l}\text { - Pain } \\
\text { - Disability } \\
\text { - Range of motion }\end{array}$ & $\begin{array}{l}\text { No significant differences in shoulder pain, disability, or } \\
\text { range of motion }\end{array}$ & $\begin{array}{l}\text { Level } 2 \\
\text { [mid-level] } \\
\text { evidence }\end{array}$ \\
\hline Hsieh $^{15}$ & 70 & $\begin{array}{l}\text { Hyaluronic acid } \\
\text { injections to physical } \\
\text { therapy }\end{array}$ & $\begin{array}{l}\text { - Pain } \\
\text { - Disability } \\
\text { - Range of motion } \\
\text { - Quality of life }\end{array}$ & $\begin{array}{l}\text { No significant difference in improvement in range of } \\
\text { motion, pain, disability, or quality of life at } 3 \text { months }\end{array}$ & $\begin{array}{l}\text { Level } 2 \\
\text { [mid-level] } \\
\text { evidence }\end{array}$ \\
\hline Seiji et al $^{16}$ & 2,120 & $\begin{array}{l}\text { Hyaluronate injection } \\
\text { vs. Placebo or steroid } \\
\text { injections }\end{array}$ & $\begin{array}{l}\text { - } \text { Global pain score } \\
\text { - Total function score } \\
\text { - Shoulder movement } \\
\text { Quality of life }\end{array}$ & $\begin{array}{l}\text { Compared to placebo } \\
\text { Hyaluronate injections associated with } \\
\text { 1- improvement in global pain scores (odds ratio } 1.84 \text {, } \\
95 \% \text { CI } 1.49-2.26 \text { ) but no improvement in pain intensity } \\
\text { 2- improvement in total function score (standard mean } \\
\text { difference } 0.36,95 \% \text { CI } 0.01-0.7, p=0.04 \text { ) } \\
\text { 2-no clinically significant difference in overall shoulder } \\
\text { movement } \\
\text { 3-no significant difference in adverse events }\end{array}$ & $\begin{array}{l}\text { Level } 2 \\
\text { [mid-level] } \\
\text { evidence }\end{array}$ \\
\hline
\end{tabular}


Some electrotherapy modalities may improve pain and function in patients with adhesive capsulitis (level 2 [mid-level] evidence). ${ }^{10}$

A systematic review of trials that included randomized or quasi-randomized trials evaluating electrotherapy modalities in 1,249 patients >16 years old with adhesive capsulitis. Most trials had one or more limitations including unclear or inadequate allocation concealment, lack of blinding, small sample size. Meta-analysis was precluded by heterogeneity in interventions and outcome measures. Several electrotherapy modalities improved pain and/or function in single small trials. Benefits included significant improvement in pain and function at 4 weeks and 4 months with low-level laser therapy plus home exercises vs. placebo plus home exercises in 1 trial with 63 patients. In addition, there was improved function at 2 weeks and 3 months with addition of multiple electrotherapies (therapeutic ultrasound plus transcutaneous electrical nerve stimulation [TENS] plus hot pack) to home exercises in 1 trial with 41 patients. There was also improved function at 4-8 weeks with addition of continuous short-wave diathermy to exercise in one trial with 30 patients. Moreover, the pain decreased at end of treatment with phonophoresis (alone or in combination with continuous short-wave diathermy) plus exercise vs. placebo plus exercise in one trial with 45 patients. The review showed higher chances of treatment success at 6 days with low-level laser therapy vs. placebo in one trial with 40 patients. Electrotherapy was associated with decreased pain but no significant increase in total recovery of joint function at 2 weeks with low-frequency $(100$ hertz $[\mathrm{Hz}])$ pulsed electromagnetic field therapy vs. placebo in 1 trial with 32 patients. $^{10}$

The review discussed multiple electrotherapies (therapeutic ultrasound plus TENS plus hot pack) plus home exercises significantly improved function at 2 weeks but had no significant difference in function at 3 months vs. sodium hyaluronate injection plus home exercises in 1 trial with 45 patients. Continuous shortwave diathermy plus exercises significantly decreased treatment success at 2 weeks vs. deep friction massage plus exercises in one trial with 40 patients. ${ }^{10}$

\section{Invasive treatment}

Insufficient evidence to compare manipulation to arthroscopic release for recalcitrant adhesive capsulitis. ${ }^{11}$

A systematic review of 22 studies reporting outcomes after arthroscopic capsular release or manipulation under regional or general anesthesia in 989 patients with recalcitrant adhesive capsulitis showed insufficient evidence of the presence of difference between manipulation and arthroscopic release. ${ }^{11}$ The comparisons were mostly indirect comparisons.
In another meta-analysis study, researchers showed variation in outcome measures and lack of adequate data reporting; $\mathrm{p}$-values were mostly not reported. There was a prospective cohort study (43 patients with diabetic adhesive capsulitis, 47 shoulders) that compared manipulation under anesthesia (MUA) (24 shoulders) to capsular release performed only if manipulation under anesthesia failed to improve shoulder function (CRMUA) (12 shoulders) or initial capsular release (CR) (11 shoulders). The study measured improvement in mean Constant score (assesses pain, range of motion, strength, and activities of daily living; higher score indicates better outcome). The results were 47 points in MUA/CR-MUA group, 33 points in CR group. ${ }^{10}$ in indirect comparisons, arthroscopic capsular release and manipulation under anesthesia have similar patient-reported outcomes. ${ }^{11}$

Hydrodistention with joint manipulation under interscalene block may improve pain and function up to 12 weeks compared to single intra-articular corticosteroid injection in patients with adhesive capsulitis (level 2 [mid-level] evidence). ${ }^{12}$

Hydrodistention was associated with significant improvements in mean pain and Constant score up to 12 weeks and improved patient satisfaction, forward flexion, external rotation, and internal rotation up to 6 weeks. However, there were no significant differences in mean pain and constant score at 24 and 48 weeks as well as patient satisfaction, forward flexion, external rotation, and internal rotation at 12,24 and 48 weeks. These results were based on randomized trial (without intentionto-treat analysis) that included 136 patients (mean age 53 years) with adhesive capsulitis for $\geq 3$ months. Patients were randomized to hydrodistention with joint manipulation under interscalene block vs. single intraarticular corticosteroid injection and followed for 1 year. Hydrodistention injection was mixture of $1 \mathrm{~mL}$ triamcinolone $(40 \mathrm{mg}), 10 \mathrm{~mL} 1 \%$ lidocaine, and $30 \mathrm{~mL}$ saline, while intra-articular injection was mixture of $1 \mathrm{~mL}$ triamcinolone $(40 \mathrm{mg}$ ) and $5 \mathrm{~mL} 1 \%$ lidocaine. All patients received oral nonsteroidal anti-inflammatory drugs for 2 weeks after procedure and rehabilitation exercises for 1 month (starting immediately after procedure in hydrodistention group and 2 weeks later in corticosteroid injection group). $11 \%$ of patients were lost to follow-up and excluded from analysis. ${ }^{12}$

\section{DISCUSSION}

Manual therapy and exercise in combination and alone have limited evidence to guide treatment of adhesive capsulitis. $^{7} \quad$ Intra-articular corticosteroid injections combined with shoulder mobility and stretching exercises are more effective in providing short-term (4-6 weeks) pain relief and improved function compared to shoulder mobility and stretching exercises alone. The intensity of the exercises should be determined by the patient's tissue irritability level. 
On the other hand ultrasonography-guided intra-articular steroid injection may improve pain and function within 3 weeks after injection compared to blind injection. ${ }^{10}$ Single intra-articular steroid injection may slightly reduce pain and improve function in patients with adhesive capsulitis of shoulder. Intra-articular and combined intraarticular/rotator cuff interval corticosteroid injections may both reduce pain up to 12 weeks in adults with adhesive capsulitis of shoulder. Shortwave diathermy, ultrasound, or electrical stimulation may be used in combination with mobility and stretching exercises to reduce pain and improve shoulder ROM in patients with adhesive capsulitis. Joint mobilization procedures primarily directed to the glenohumeral joint to reduce pain and increase motion and function in patients with adhesive capsulitis.

Ultrasonography-guided corticosteroid injection may reduce pain compared to oral aceclofenac in patients with adhesive capsulitis. ${ }^{10}$ Multiple intra-articular steroid injections might be more effective than oral steroids for some outcomes in patients with adhesive capsulitis. Oral steroids may provide short-term improvement in pain and disability but no effect 3 weeks after steroid withdrawal.

On the other hand, Intra-articular injection of hyaluronate plus capsular distention appears as effective as triamcinolone injection for shoulder pain and disability. ${ }^{10}$ Suprascapular nerve block may reduce pain up to 12 weeks in adults with adhesive capsulitis insufficient evidence to compare manipulation to arthroscopic release for recalcitrant adhesive capsulitis. ${ }^{11}$ The addition of manipulation under anesthesia to home exercise may not improve outcomes for patients with frozen shoulder. ${ }^{11}$ Translational manipulation under anesthesia directed to the glenohumeral joint can be considered in patients with adhesive capsulitis who are not responding to conservative interventions.

Extracorporeal shockwave therapy might improve shoulder function compared to oral prednisolone in patients with primary adhesive capsulitis. Acupuncture associated with greater improvement in pain and disability compared with physical therapy alone at 12 weeks after treatment in adults with adhesive capsulitis.

\section{CONCLUSION}

On the basis of current clinical evidence, this systematic review suggests that there is no strong evidence to support or refute the current practice in term of adhesive capsulitis management. As there is a need of further reseach in this issue and to have clear uniformed prospective about the adhesive capsulitis.

Funding: No funding sources Conflict of interest: None declared

Ethical approval: The study was approved by the Institutional Ethics Committee

\section{REFERENCES}

1. Hand GC, Athanasou NA, Matthews T, Carr AJ. The pathology of frozen shoulder. J Bone Joint Surg Br. 2007;89(7):928-32.

2. Arkkila PE, Kantola IM, Viikari J.S, Rönnemaa T. Shoulder capsulitis in type I and II diabetic patients: association with diabetic complications and related diseases. Ann Rheum Dis. 1996;55(12):907-14.

3. Balci N, Balci MK, Tüzüner S. Shoulder adhesive capsulitis and shoulder range of motion in type II diabetes mellitus: association with diabetic complications. J Diabetes Complications. 1999;13(3):135-40.

4. Kang JH, Sheu JJ, Lin HC. Increased risk of stroke after adhesive capsulitis: a population-based study. Stroke. 2010;41(5):1044-7.

5. Neviaser RJ. The Journal of Musculoskeletal Medicine. Cliggott Publishing Company. 1992;9(2):62.

6. Dias R, Cutts S, Massoud S. Frozen shoulder. BMJ. 2005;331:1453-6.

7. Page MJ, Green S, Kramer S, Johnston RV, McBain B, Chau M, Buchbinder R. Manual therapy and exercise for adhesive capsulitis (frozen shoulder). Cochrane Database Syst Rev. 2014;26(8):CD011275.

8. Widiastuti-Samekto M, Sianturi GP. Frozen shoulder syndrome: comparison of oral route corticosteroid and intra-articular corticosteroid injection. Med J Malaysia. 2004;59(3):312-6.

9. Buchbinder R, Green S, Youd JM, Johnston RV. Oral steroids for adhesive capsulitis. Cochrane Database Syst Rev. 2006;(4):CD006189.

10. Grant JA, Schroeder N, Miller BS, Carpenter JE. Comparison of manipulation and arthroscopic capsular release for adhesive capsulitis: a systematic review. J Shoulder Elbow Surg. 2013;22(8):113545.

11. Mun SW, Baek CH. Clinical efficacy of hydrodistention with joint manipulation under interscalene block compared with intra-articular corticosteroid injection for frozen shoulder: a prospective randomized controlled study. J Shoulder Elbow Surg. 2016;25(12):1937-43.

12. Page MJ, Green S, Kramer S, Johnston RV, McBain B, Buchbinder R. Electrotherapy modalities for adhesive capsulitis (frozen shoulder). Cochrane Database Syst Rev. 2014;(10):CD011324.

13. Yaying S, Peng Z, Shaohua L, Hong L, Jia J, Shiyi C, et al. Intra-articular Steroid Injection for Frozen Shoulder A Systematic Review and Meta-analysis of Randomized Controlled Trials With Trial Sequential Analysis. AJSM. 2016.

14. Prestgaarda T, Wormgoora MEA, Haugena S, Harstada H, Mowinckelc P, Broxd JI. Ultrasoundguided intra-articular and rotator interval corticosteroid injections in adhesive capsulitis of the shoulder: a double-blind, sham-controlled randomized study. PAIN. 2015;156:9. 
15. Hsieh L-F, Hsu W-C, Lin Y-J, Chang H-L, Chen CC, Huang V. Addition of Intra-articular Hyaluronate Injection to Physical Therapy Program Produces No Extra Benefits in Patients With Adhesive Capsulitis of the Shoulder: A Randomized Controlled Trial. Arch Phys Med Rehabil. 2012; 93.

16. Seiji S, Takefumi F, Shigeru K. Therapeutic Effects of Hyaluronate Injections in Patients With Chronic Painful Shoulder: A Meta-Analysis of Randomized
Controlled Trials. Arthritis Care Res. 2010;62:100918.

Cite this article as: Almashni RA, Calacattawi AW, Almeshal MA, Alsharif EJ, Hijazi MW, Abdulwahab SA, et al. Current management of shoulder adhesive capsulitis: a randomized, triple-blind placebocontrolled trial. Int J Community Med Public Health 2018;5:3678-85. 